\title{
Buzzing Wild Bee Visits Enhance Seed Set in Eggplant, Solanum melongena
}

\author{
U. J. M. Shanika R. Jayasinghe, T. H. Saumya E. Silva, and W. A. Inoka P. Karunaratne \\ Department of Zoology, Faculty of Science, University of Peradeniya, 20400 Peradeniya, Sri Lanka \\ Correspondence should be addressed to W. A. Inoka P. Karunaratne; inokap@pdn.ac.lk
}

Received 13 February 2017; Accepted 9 April 2017; Published 25 May 2017

Academic Editor: Jacques Hubert Charles Delabie

Copyright (C) 2017 U. J. M. Shanika R. Jayasinghe et al. This is an open access article distributed under the Creative Commons Attribution License, which permits unrestricted use, distribution, and reproduction in any medium, provided the original work is properly cited.

\begin{abstract}
Sixty percent of the angiosperms with poricidal anthers are buzz-pollinated by bees (Hymenoptera: Apoidea: Apiformes). Plant taxa with Solanum-type flowers have larger anthers and shorter filaments. Solanum melongena (Solanaceae) is more commonly and efficiently pollinated by buzz pollinators. The present study documented bees and their diurnal pattern of visitation to flowers, relationship between their handling time and flower age, and the effect of bee visits on fruit and seed set in S. melongena in two sites in Kandy District. Efficiency of buzz pollination over pollination in the absence of bees was determined using open buds and buds covered with pollinator exclusion bags. On average, 150 days were taken to complete the life cycle of Solanum melongena. Three buzzing bees and two nonbuzzing bees in site I and five buzzing bees and two nonbuzzing bees in site II were recorded. Handling time of Pachynomia sp. and Hoplonomia westwoodi indicates that bees spend more time at new flowers than at old flowers. Handling time is higher in the smaller bee, Pachynomia sp., than in the larger bee, H. westwoodi. Statistical data on pollinator exclusion experiment revealed that the fruit set and seed set of $S$. melongena are enhanced by buzz-pollinating bees.
\end{abstract}

\section{Introduction}

Pollination is one of the most important plant-animal interactions for reproduction of plants [1]. Pollinator organisms are engrossed to pollinate $35 \%$ of the plants cultivated in the world [2]. Among them, more than 1500 plant species are pollinated by bees [3]. Crops such as coffee (Coffea spp.) [4, 5], melon (Citrullus lanatus) [6], tomato (Solanum lycopersicum) [7], sunflower (Helianthus annuus) [8], canola (Brassica spp.) [9], and blueberries (Vaccinium spp.) [10] are common examples of bee-pollinated crops. Among pollinator bees, certain clades such as carpenter bees (Xylocopini), bumble bees (Bombini), and orchid bees (Euglossini, Centridini, and Augochlorini) are able to vibrate flowers to collect pollen. Since this strong rapid vibrations made a buzzing sound, this phenomenon is known as "buzz pollination" [11].

Buzz pollination can be seen in 357 genera of plants representing 54 families of angiosperms [12]. Those plants have poricidal anthers, which mean anthers do not split open to release pollen but need natural or artificial vibrations to release pollen through their apical pores [13]. As pollen is well hidden and available only to specialized buzzing bees that vibrate the anthers of flowers, pollen waste is very low in buzzpollinated flowers [12]. Most buzz-pollinated flowers have few stamens [14] and downward facing position which is positive discrimination to hanging of bees while they buzz [15]. The strong yellow colour of the anthers contrasting markedly with the usual purple or white corolla is a characteristic of buzzpollinated flowers. Flowers with such strongly contrasting colours within the visible spectrum of light have been shown to be attractive to pollen-gathering bees even in the absence of reinforcing UV patterns [11].

Solanaceae is one of examples of plant families that are pollinated by buzzing bees. Though Solanum flowers lack nectar, they afford a moderately wealthy pollen load for bees that visit them [16]. Solanum is the second largest genus of flowering plants which contains more than 2000 species [17]. It includes major economical crop species such as Solanum melongena (eggplant) and S. tuberosum (potato). The eggplant, S. melongena (Solanaceae), is a major vegetable 
crop in many countries of the world [18]. It is a delicate, perennial, annual tropical plant native to Africa and Asia [19]. Fruits are formed due to both cross pollination [12] and selfpollination $[17,20]$. However, according to Buchmann and Cane [17], S. melongena is more commonly and efficiently pollinated by buzz pollinators. Several studies had been carried out to test the effect of self-pollination on seed set in S. melongena [21-24] in temperate countries of the world. However, very few studies $[25,26]$ have been conducted in tropical countries on the pollination ecology of $S$. melongena. The present study was designed to fill this vacuum, with the aim to (i) identify bees visiting flowers of S. melongena and their diurnal pattern of activity, (ii) record the handling time of buzzing bees at flowers with respect to age of flowers, and (iii) determine the effect of bee visits to flowers on fruit set and seed set.

\section{Materials and Methods}

Regarding study sites, field work was conducted in Sri Lanka at two sites (Miwatura and Gelioya) in Kandy District $\left(7^{\circ} 15^{\prime} \mathrm{N}\right.$, $80^{\circ} 45^{\prime} \mathrm{E}$ ), central Sri Lanka, for a period of 10 months (from June 2008 to April 2009). The mean annual temperature and rainfall of the two sites were $41^{\circ} \mathrm{C}$ and $700 \mathrm{~mm}$ (source: Natural Resources Management Center, Peradeniya), respectively. The site at Miwatura is a semiagriculture research field of University of Peradeniya, located in the western valley of the Mahaweli River, in close proximity to a Peradeniya, Gampola main road. In this site, several vegetable crops belonging to Solanaceae and Leguminosae had been cultivated from time to time for research purposes. The site at Gelioya is surrounded by a paddy field, a home garden, and plots of vegetable crops mainly belonging to Solanaceae, Cucurbitaceae, and Leguminosae.

2.1. Field Preparation and Planting of S. melongena Seedlings. From June 2008 to September 2008, field was prepared and planted at Miwatura site. First, seeds of S. melongena were planted in seed beds following agricultural recommendations. Then, 20-day-old germinated seedlings were cultivated in the field for field experiments. Depending on the availability of land, an area of $12 \mathrm{~m} \times 15 \mathrm{~m}$ in Miwatura site was selected and $50 \mathrm{~S}$. melongena plants were cultivated. At Gelioya site, 80 S. melongena plants were present in a $15 \mathrm{~m}$ $\times 15 \mathrm{~m}$ area.

2.2. Recording of the Times of Stigma Receptivity and Anther Dehiscence. Times of stigma receptivity and anther dehiscence were observed in freshly opened five flowers of $S$. melongena. The time of stigma receptivity was determined by observing the stigma through a hand lens every 10 minutes from 7.00 a.m. to 3.30 p.m. The stigma was touched by a needle tip to observe the stickiness and was considered as the time of stigma receptivity. The time of anther dehiscence was observed by shaking the flower onto a white paper every 10 minutes from 7.00 a.m. The time at which pollen was released and collected onto the white paper was considered as the time of anther dehiscence.
2.3. Study of Bee Visitors, Species Composition, and Their Diurnal Activity. Over a period of 5 months (September 2008 to January 2009), bees visiting S. melongena flowers were observed at the two sites. Bees visiting flowers of S. melongena were observed for ten sunny days until no new species were recorded. Bees that visited flowers were categorized into two groups as buzzing or nonbuzzing bees. Buzzing bees were identified by carefully listening to the sound they produce at the time of pollen collection. Bees that collect pollen from anthers without producing a sound were considered nonbuzzing bees. Bees collected using sweep net were curated and identified using published keys [27]. Reference specimens were logged in the Invertebrate Systematics and Diversity Facility (ISDF) of the Department of Zoology, University of Peradeniya.

The time of visits of each species was observed from 07:00 to 15:30 at 30-minute intervals on two sunny days at the Miwatura site and four sunny days at the Gelioya site. However, no attempt was made to count the number of individuals (abundance) of different species visiting flowers.

2.4. Determining the Number of Pollen Grains in Anthers of Flowers of Different Age. Pollen from 20 flowers at different age (five flowers from each stage) was counted to determine the relationship between buzzing time and available pollen grains at Gelioya site. Flowers at four different ages, newly opened flowers, one-day-old flowers, two-day-old flowers, and flowers that were more than two days old, were selected. Newly opened flowers were observed on 27 September 2008. On the following day, these flowers were considered to be 1 day old and, on the third day, these flowers were considered to be 2 days old. On the fourth day, these 20 flowers were considered to be $>2$ days old. From each flower, one anther was removed and cut open longitudinally to collect all the grains. From each anther, the pollen grains were put into $1.5 \mathrm{ml}$ of $50 \%$ alcohol in separate watch glasses. From each sample, $1 \mathrm{ml}$ of the mixture (after stirring) was transferred into McMaster Chamber. The average number of pollen grains in each chamber was counted. The available pollen grains per $1 \mathrm{ml}$ of the four mixtures were calculated.

2.5. The Relationships between the Handling Time of Bees at Flowers and Age of Flowers. Handling time (total time that a particular bee buzzes at a flower during a single visit) was recorded for two of the common buzzing bee species (Hoplonomia westwoodi and Pachynomia sp.) at the Gelioya site. Flowers of different ages, newly opened, oneday-old, two-day-old, and more than two-day-old flowers, were selected by following the above-mentioned way. Flowers of different age groups were tagged using different coloured tags. Five flowers were selected from each age category and the handling time (in seconds) in each of the selected flowers by the two common bee species was recorded. The procedure was followed on two sunny days for $H$. westwoodi (25 December 2008 and 26 December 2008) and Pachynomia sp. (10 January 2009 and 23 January 2009). Ten specimens of each of the two common female (male bees do not buzz at flowers to collect pollen) buzzing bee species were measured for body length to investigate the difference between the 
body lengths of the two buzzing bee species. The relationship between the handling time and the mean body size (body length from the anterior end of the head to the posterior end of the tip of abdomen) of two more common bee species was also determined.

2.6. Determining the Effect of Bee Visits to Flowers on Fruit Set and Seed Set. Field trials were conducted (from December 2008 to April 2009) at the Gelioya site to determine the efficiency of buzz pollination over pollination in the absence of bees on fruit set and seed set. A sample of 50 bunches of flower buds of $S$. melongena were selected for the study. Of the selected 50 bunches, 25 bunches were tagged and left open for bees to visit. Numbers of fruits formed by each bunch were recorded. Their length (from proximal end to the distal end) and weight of fruits were measured. Fruits were hold until they were rotten and the numbers of seeds produced by each fruit were counted. The remaining 25 bunches were tagged and bagged using pollinator exclusion bags to exclude bees from reaching flowers. These closed flowers were assumed to get self-pollinated in the absence of bees. Number of fruits produced, their size and weight, and the numbers of seeds in each fruit were recorded as in the previous trial.

2.7. Data Analysis. Data analysis was carried out using Microsoft Excel 2008 and Minitab version 16. Two-sample $t$ test was carried out using Minitab 16 to determine whether there is a significant difference between handling times of the two common buzzing bees at flowers of each age category and the difference between the body lengths of the two common buzzing bee species at $95 \%$ confidence interval. Difference between the fruit length and weight and number of seeds produced from fruits of the two trials was also analyzed using two-sample $t$-test.

\section{Results}

3.1. Species Composition and Diurnal Pattern of Bee Visitation. A total of seven bee species visited flowers of $S$. melongena at the two sites. The pollen bees, belonging to family Halictidae (Hoplonomia westwoodi, Patellapis kaluterae, and Pachynomia sp.) and family Apidae (Amegilla comberi and Xylocopa tenuiscapa), buzzed at the anthers of $S$. melongena flowers. The honeybee species, Apis cerana, and Trigona iridipennis were the non-buzzing bees. Apis cerana collected pollen by damaging the anther base and milking the anthers and $T$. iridipennis collected pollen fallen around anther cones and on flower petals. The site at Gelioya harbored all seven species of bees, while the site at Miwatura recorded only five bee species except the two buzzing bees, Pachynomia sp. and $X$. tenuiscapa. Though counts of bees were not made, according to the close observations, common buzzing bees visiting flowers at Miwatura site were $H$. westwoodi and in Gelioya site they were $H$. westwoodi and Pachynomia sp. The activity periods of bees at the Miwatura site and Gelioya site, respectively, are shown (Figure 1) and indicate that the peak activity period of buzzing bees and nonbuzzing bees and also between the two sites is different. At Miwatura site, bees were very active between 09:00 and 12:00 hours and continued till 14:00. At Gelioya site, they were very active from 08:00 to 10:30 and continued until 11:30 and there were no bees visiting flowers after 11:30. At Gelioya site, six bee species (except Xylocopa tenuiscapa) were recorded from flowers daily. Buzzing bees were the first to visit Solanum flowers and were followed by nonbuzzing bees. Observation of the activity of individual bees at Miwatura site indicated that $H$. westwoodi was the most active bee species from 08:00 to 14:00 of the day. However, activity of this species was limited to 1-2 hours at the Gelioya site. Closer examination of the anther and stigma of flowers indicated that the stigma remains receptive from 08:00 to 11:00 in the morning and the anthers open around 08:00. This period correlated with the period of high bee activity in both sites.

3.2. Number of Pollen Grains per Anther and Handling Time of Bees with Flower Age. Solanum melongena has triporate type pollen. The amount of pollen available in the anthers of flowers of the four age groups was estimated to find out the relationship between handling time by bees and the amount of pollen available in anthers. The highest amount of pollen was available in new anthers ( $>200,000$ grains), while the lowest amount of pollen ( $<50,000$ grains) was found in anthers that are more than two days old, indicating a gradual decrease in the available pollen grains per anther with age of flower (Figure 2).

Two species of common buzzing bees, Pachynomia sp. and $H$. westwoodi, at Gelioya site were selected to study the handling time of each species at anthers of S. melongena flowers of different age group. The averaged handling time of Pachynomia sp. and H. westwoodi is given (Figure 3) and shows that buzzing time of Pachynomia sp. was highest at flowers of all four age groups compared to that of $H$. westwoodi. Results of paired $t$-test revealed that the buzzing times of the two species of bees differ significantly $(p<0.05)$ at flowers of each age group. Both species of bees buzzed for longer time on new flowers with large amount of pollen and the time decreases with the age of flower (amount of pollen). The body length of $H$. westwoodi is $8.50 \mathrm{~mm}$ while that of Pachynomia sp. is $7.00 \mathrm{~mm}$, indicating that the larger $H$. westwoodi buzz at flowers for shorter periods, while the smaller Pachynomia sp. buzz for longer periods at flowers.

3.3. Effect of Bee Visits on Fruit Set and Seed Set. The percentage of fruit production was higher (62.5\%) in open bunches of flower buds that were made available for bees to visit than in closed bunches of flower buds (18.9\%). The mean length ( \pm standard deviation) of fruits developed from closed flowers was $16.14 \pm 3.29 \mathrm{~cm}$ and that of open flowers was $16.185 \pm 1.87 \mathrm{~cm}$. Therefore, the difference of the fruits in length was not significant $(p=0.96)$. Mean weight $( \pm$ standard deviation) of fruits produced from closed flowers was similar to that of those produced from open flowers $(122.12 \pm 22.66 \mathrm{~g}$ and $122.37 \pm 29.69 \mathrm{~g}$, resp. $)$ and was not significant $(p=0.98)$. However, the number of seeds produced by the fruits of the two treatments was significantly different $(p<0.05)$ and fruits produced from open flowers had large number of seeds (mean $\pm=1250 \pm 265$ ) compared to that of closed flowers (mean $\pm=723 \pm 265$ ). 


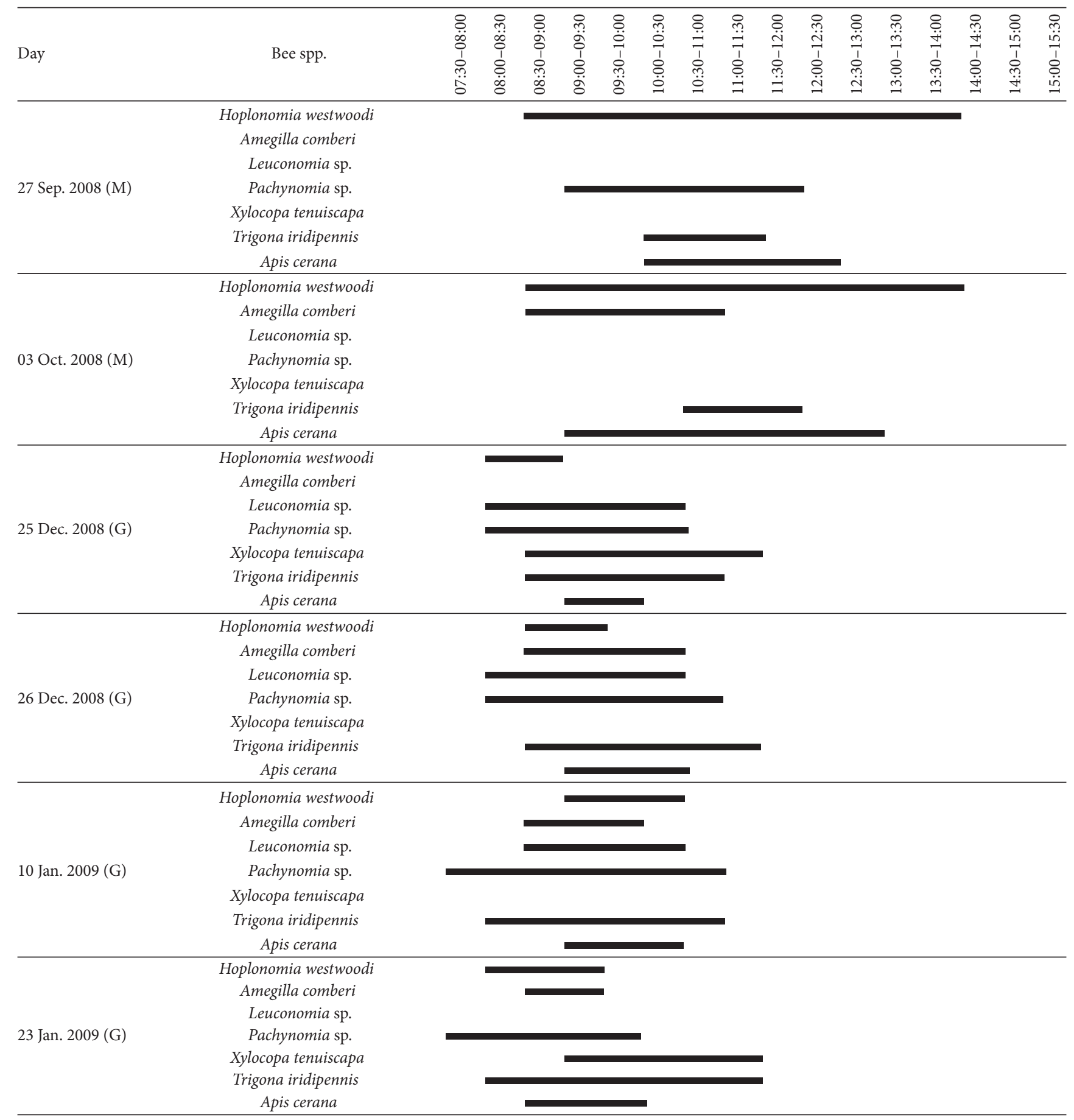

Figure 1: Activity period of bees at Miwatura (M) and Gelioya (G) sites in two and four sunny days, respectively, at flowers of S. melongena. Range in temperature $\left({ }^{\circ} \mathrm{C}\right)$, rainfall $(\mathrm{mm})$, and relative humidity during the time period of observations for the six days: 27 September $2008-20.80-31.80^{\circ} \mathrm{C}, 0.0 \mathrm{~mm}$, and $62-65 ; 03$ October $2008-20.00-31.70^{\circ} \mathrm{C}, 0.0 \mathrm{~mm}$, and $54-61 ; 25$ December $2008-21.40-29.50^{\circ} \mathrm{C}, 0.0 \mathrm{~mm}$, and 55-57; 26 December 2008-19.40-30.80 C, $0.0 \mathrm{~mm}$, and 50-53; 10 January 2009-20.90-29.80 ${ }^{\circ} \mathrm{C}, 0.0 \mathrm{~mm}$, and 62-65; and 23 January 2009-17.00-30.00 $\mathrm{C}, 0.0 \mathrm{~mm}$, and 51-68.

\section{Discussion}

Although S. melongena flowers lack nectar and have terminal anther pores [28], they were visited by many bee species for the rich pollen resource. Studies conducted in different parts of Sri Lanka from 2001 to 2004 list 16 species of bees visiting flowers of $S$. melongena $[29,30]$. During the present study, S. melongena flowers attracted seven species of wild bees. Among them, only five bee species buzzed at flowers. But the other two honeybees did not buzz at flowers to collect 


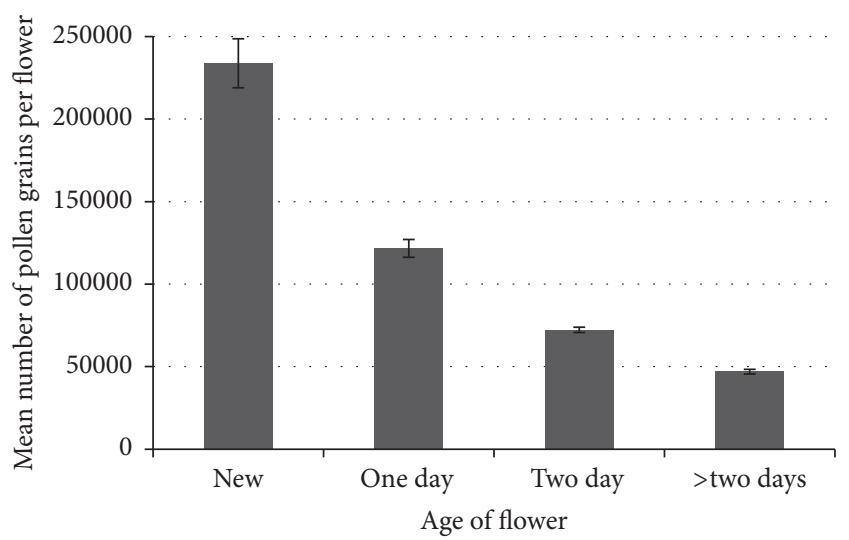

FIGURE 2: Number of pollen grains per anther with the age of flowers of different ages.

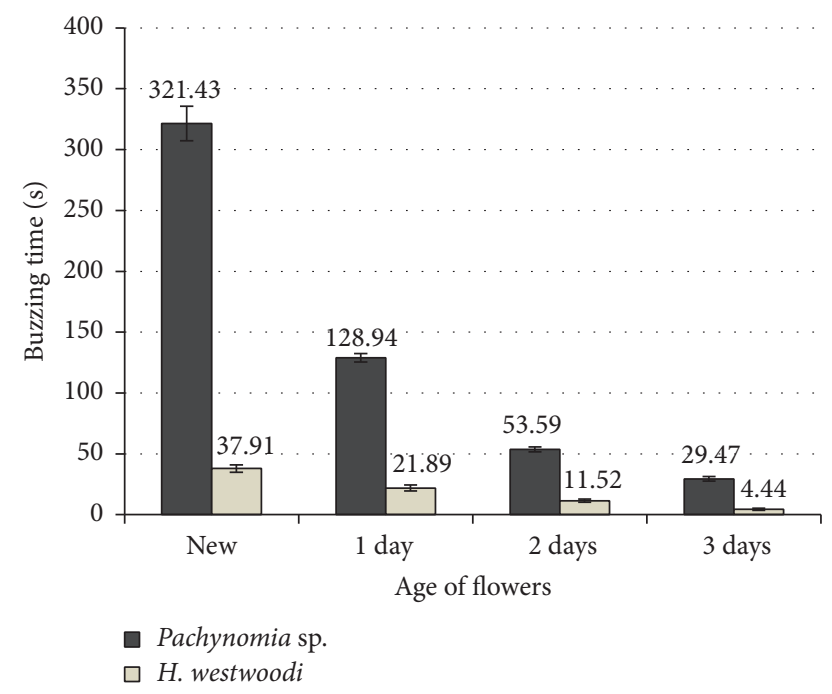

Figure 3: Comparison of buzzing times of Pachynomia sp. and $H$. westwoodi bees at $S$. melongena flowers of the four age groups (new, 1-day-old, 2-day-old, and 3-day-old flowers).

pollen from anthers [12]. Among the five buzzing bees, three belonging to family Halictidae contain the highest number of bee species of Sri Lanka. The other two buzzing bees belong to family Apidae. Buzzing bees were the first to arrive at flowers early in the morning and these were followed by nonbuzzing bees. Thereafter, both groups were found together actively collecting pollen from flowers. As observed by Wanigasekara and Karunaratne [31], buzzing by the first bee species to arrive at flowers of $S$. violaceum released pollen from the apical pores of anthers, initiating pollen release and making opened anthers available to nonbuzzing bees. The stingless bees, Trigona iridipennis, were seen collecting pollen fallen around the anther cones and petals. According to Anderson and Symon [28], species as Trigona are simply pollen thieves, although they do not pierce the flowers to get pollen. They collect pollen spread over the flowers which was released due to the activities of the vibratile pollinators and they also foraged on the stigma [28].
Among two study sites, Gelioya site contained all recorded seven species including two additional species compared to those recorded at Miwatura site. This may be because the Gelioya site is in a village setting with diverse vegetation comprising cultivated crops and natural vegetation belonging to many plant families that provide a continuous year-round supply of food for the native wild bees. In contrast, except for the area under cultivation, Miwatura site has a dense cover of the invasive grass, Panicum maximum, which has become very difficult to control. Absence of cultivated and natural vegetation which serves as food plants and nesting grounds for bees at this site may have resulted in paucity of bees. A previous survey of bees conducted at the Miwatura site from 2001 to 2003 [32], when the area was rich in annual and perennial broadleaf herbaceous weeds and cultivated plants, recorded five species of buzzing bees, Amegilla comberi, Amegilla sp., Gnathonomia nasicana, Leuconomia sp., and $H$. westwoodi, from S. melongena.

The peak activity of buzzing bees coincided with the time of anther opening and stigma receptivity enabling cross pollination of $S$. melongena flowers by bees. A similar study conducted in Southern Costa Rica under tropical weather conditions indicated a similar high bee activity period during anther dehiscence and stigma receptivity in flowers of $S$. wendlandii, which is an ornamental plant [33]. A similar field study conducted in the central Kegalle District of Sri Lanka by Wanigasekara and Karunaratne [31] also gave a similar finding. Although the findings indicate that stigma receptivity and release of pollen occur at the same time, there is a lesser chance for self-pollination as the stigma of $S$. melongena protrudes over the anther, preventing the possibility of self-pollination. But buzzing bee activity coincides with the time of stigma receptivity and release of pollen indicates the high possibility of both self-pollination and cross pollination mediated by bees.

The observation that bees buzzed longer on new flowers which decreased with increasing age of flowers was similar to study done by Shelly and Villalobos [33] for bumble bees. According to them, bees rejected older flowers with pale colours and different floral shape. The pollen-collecting bees are sensitive to the high availability of resources [31]. But, according to Burkart et al. [34], bees are unable to make long-distance assessment of pollen availability; hence, they visit new and old flowers at the same frequency during day time. Upon alighting on a flower, bees adjust the time they spend at an individual flower, based on pollen availability. These findings agree with those of the present study where both buzzing bee species showed highest handling time at new flowers compared to low handling time at flowers that are more than two days old likely due to the high pollen availability in new flower anthers compared to old flower anthers. King and Buchmann [35] stated that large amounts of pollen (72,000 grains) are released in initial sonication of new flowers and with the age of flower, the amount of pollen in flowers decreased. Harder and Barclay [36] also reported that flower's age significantly affects the removal of pollen by bees. The relationship between buzzing time and availability of pollen in anthers of different ages reported in this study agrees with most of the previous findings. 
The present study further confirms the availability of large amount of pollen (200,000 grains per anther) in new flowers compared to flowers over two days old $(<50,000$ grains per anther). Therefore, it is evident that bees spend more time at new flowers which are rich in pollen as a cost-effective measure. But this finding is contradictory to Buchmann [12] who reported that handling time is shorter at new flowers than at older flowers.

The finding that the larger bee, $H$. westwoodi, spends less time buzzing at flowers than the smaller bee, Pachynomia sp., agrees with studies conducted in Australia by Anderson and Symon [28]. They reported that the larger blue banded bee, Amegilla sp., spent less time at flowers compared to Nomia sp. which is comparatively smaller. Similar observations have been made by Wanigasekara and Karunaratne [31] for $S$. violaceum flowers buzzed by larger bee, $H$. westwoodi, and a comparatively smaller bee, Patellapis kaluterae. This result is also equivalent to explanation done by Wanigasekara and Karunaratne [31] as vibration done by buzzing bees may singly or collectively be based on their body size. It is noteworthy that the buzzing time of $H$. westwoodi is very much similar and follows the same pattern at flowers of both S. violaceum and S. melongena irrespective of the size of flowers.

In the present study, although the number of fruits produced by open flowers was greater than that produced by closed flowers, the difference was not significant. According to Buchmann [12], bees are essential to pollinate eggplant flowers efficiently. Kakizaki [20] reported that Solanum plants grown in cages without bees produced no fruits. Similar observations were made by Jones and Rosa [37] and Pal and Taller [21]. Although a large amount of pollen is released onto the stigma, in self-pollination, the fruit set is low compared to buzz pollination. Findings of Duncan et al. [38] were similar for Dianella revoluta (Phormiaceae) which is a buzz-pollinated flower. Jones and Rosa (1928) reported that plants that were isolated from insect visitors bore no fruits. Although there was no significant difference in the size of fruits produced by open and closed flowers of $S$. melongena, the number of seeds produced per fruit in open flowers was significantly higher, indicating the importance of bees. Several studies have been carried out to test the effect of selfpollination on seed set in eggplant. McGregor [22], Bailey [23], and Aizen et al. [39] reported that a large number of seeds are produced following cross pollination by bees compared to artificial pollination. Pal and Taller [21] also stated that the number of seeds per fruit is higher in crosspollinated flowers than in self-pollinated flowers.

The finding that buzz pollination enhances seed set in $S$. melongena is of significance to agriculture as S. melongena is propagated by seeds. This study, like many other similar studies, highlights the role of wild buzzing bees in the propagation of $S$. melongena, a popular vegetable crop grown extensively in Sri Lanka. Since buzzing bee species that visit $S$. melongena flowers are generalist bees, their presence can be enhanced by planting flowering plants that supply a rich source of pollen year round and providing nesting sites for ground and wood nesters in the vicinity of cultivations.

\section{Conflicts of Interest}

The authors declare that there are no conflicts of interest regarding the publication of this paper.

\section{References}

[1] C. Murcia, "Forest fragmentation and the pollination of neotropical plants," in Forest Patches in Tropical Landscapes, Island Press, London, UK, 1996.

[2] A.-M. Klein, B. E. Vaissière, J. H. Cane et al., "Importance of pollinators in changing landscapes for world crops," Proceedings of the Royal Society B: Biological Sciences, vol. 274, no. 1608, pp. 303-313, 2007.

[3] D. W. Roubik, Pollination of Cultivated Plants in The Tropics, Food \& Agriculture Orgnization, 1995.

[4] A.-M. Klein, I. Steffan-Dewenter, and T. Tscharntke, "Bee pollination and fruit set of Coffea arabica and C. canephora (Rubiaceae)," American Journal of Botany, vol. 90, no. 1, pp. 153$157,2003$.

[5] D. W. Roubik, "The value of bees to the coffee harvest," Nature, vol. 417, no. 6890, p. 708, 2002.

[6] R. Winfree, N. M. Williams, J. Dushoff, and C. Kremen, "Native bees provide insurance against ongoing honey bee losses," Ecology Letters, vol. 10, no. 11, pp. 1105-1113, 2007.

[7] O. MacIas-Macias, J. Chuc, P. Ancona-Xiu, O. Cauich, and J. J. G. Quezada-Euán, "Contribution of native bees and Africanized honey bees (Hymenoptera: Apoidea) to Solanaceae crop pollination in tropical México," Journal of Applied Entomology, vol. 133, no. 6, pp. 456-465, 2009.

[8] S. S. Greenleaf and C. Kremen, "Wild bees enhance honey bees' pollination of hybrid sunflower," Proceedings of the National Academy of Sciences of the United States of America, vol. 103, no. 37, pp. 13890-13895, 2006.

[9] L. A. Morandin and M. L. Winston, "Wild bee abundance and seed production in conventional, organic, and genetically modified canola," Ecological Applications, vol. 15, no. 3, pp. 871881, 2005.

[10] P. G. Kevan and H. G. Baker, "Insects as flower visitors and pollinators," Annual Review of Entomology, vol. 28, no. 1, pp. 407-453, 1983.

[11] K. A. W. Buchmann, "Buzz pollination of Cassia quiedondilla (Leguminosae) by bees of the genera Centris and Melipona," Bulletin of the Southern California Academy of Sciences, vol. 73, no. 3, pp. 171-173, 1974.

[12] S. L. Buchmann, "Buzz pollination in angiosperms," in Handbook of Experimental Pollination Biology, C. E. Jones and R. J. Little, Eds., pp. 73-133, Van Nostrand Reinhold, New York, NY, USA, 1983.

[13] C. D. Michener, "An interesting method of pollen collecting by bees from flowers with tubular anthers," Revista de Biología Tropical, vol. 10, pp. 167-175, 1962.

[14] S. Vogel, "Evolutionary shifts from reward to deception in pollen flowers," in The Pollination of Flowers by Insects, vol. 6 of Linnean Society Symposium, pp. 89-96, 1978.

[15] S. A. Corbet, H. Chapman, and N. Saville, "Vibratory pollen collection and flower form: bumble-bees on Actinidia, Symphytum, Borago and Polygonatum," Functional Ecology, vol. 2, no. 2, pp. 147-155, 1988.

[16] T. H. Roulston, J. H. Cane, and S. L. Buchmann, "What governs protein content of pollen: pollinator preferences, pollen-pistil 
interactions, or phylogeny?" Ecological Monographs, vol. 70, no. 4, pp. 617-643, 2000.

[17] S. L. Buchmann and J. H. Cane, "Bees assess pollen returns while sonicating Solanum flowers," Oecologia, vol. 81, no. 3, pp. 289294, 1989 .

[18] B. B. Simpson and M. C. Ogorzaly, Economic Botany Plants in Our World, University of Texas, 2nd edition, 1995.

[19] S. Asada, "Studies on year-round rearing of Japanese native bumblebees (Bombus spp.) for buzz-foraging crop pollination," Bulletin of the Kanagawa Prefecture Agricultural Research Institute, vol. 144, pp. 3-18, 2004.

[20] Y. Kakizaki, "The flowering habit and natural crossing in the egg-plant," Japan Journal, vol. 3, pp. 29-38, 1924.

[21] G. Pal and M. Taller, "Effects of pollination methods on fertilization in egg plant (Solanum melongena)," Acta Agronomica Academiae Scientiarum Hungariae, vol. 18, pp. 307-315, 1969.

[22] S. E. McGregor, Insect Pollination of Cultivated Crop Plants, U.S. Government Printing Office, Washington, DC, USA, 1976.

[23] L. H. Bailey, Experiences with Egg Plants, Agriculture Exports Statistics Bulletin 26, Cornell University, New York, NY, USA, 1891.

[24] L. Ashworth, R. Aguilar, L. Galetto, and M. A. Aizen, "Why do pollination generalist and specialist plant species show similar reproductive susceptibility to habitat fragmentation?" Journal of Ecology, vol. 92, no. 4, pp. 717-719, 2004.

[25] B. Gemmill-Herren and A. O. Ochieng, "Role of native bees and natural habitats in eggplant (Solanum melongena) pollination in Kenya," Agriculture, Ecosystems and Environment, vol. 127, no. 1, pp. 31-36, 2008.

[26] P. Nunes-Silva, M. Hrncir, C. I. Da Silva, Y. S. Roldão, and V. L. Imperatriz-Fonseca, "Stingless bees, Melipona fasciculata, as efficient pollinators of eggplant (Solanum melongena) in greenhouses," Apidologie, vol. 44, no. 5, pp. 537-546, 2013.

[27] W. A. I. P. Karunaratne and J. P. Edirisinghe, "Key to the identification of common bees of Sri Lanka," Journal of the National Science Foundation, vol. 36, no. 1, pp. 75-97, 2008.

[28] G. J. Anderson and D. Symon, "Insect foragers on solanum flowers in Australia," Annals of the Missouri Botanical Garden, vol. 75, no. 3, pp. 842-852, 1988.

[29] W. A. I. P. Karunaratne, J. P. Edirisinghe, and C. V. S. Gunatilleke, "Floral relationships of bees in selected areas of Sri Lanka," Ceylon Journal of Science, vol. 34, pp. 27-45, 2005.

[30] W. A. I. P. Karunaratne and J. P. Edirisinghe, "Diversity and floral hosts of bees in selected habitats of the Peradeniya University Park," Ceylon Journal of Science (Biological Sciences), vol. 30, no. 2002, pp. 21-36, 2002.

[31] R. W. M. U. M. Wanigasekara and W. A. I. P. Karunaratne, "Efficiency of buzzing bees in fruit set and seed set of Solanum violaceum in Sri Lanka," Psyche, vol. 2012, Article ID 231638, 7 pages, 2012.

[32] W. A. I. P. Karunaratne and J. P. Edirisinghe, "Bee diversity in a semi-agricultural field-Sri Lanka," Biodiversity, vol. 6, no. 4, pp. 17-20, 2006.

[33] T. E. Shelly and E. Villalobos, "Buzzing bees on Solanum (Solanaceae) floral choice and handling time track pollen availability," Florida Entomologist, vol. 83, no. 2, pp. 180-187, 2000.

[34] A. Burkart, C. Schlindwein, and K. Lunau, "Assessment of pollen reward and pollen availability in Solanum stramoniifolium and Solanum paniculatum for buzz-pollinating carpenter bees," Plant Biology, vol. 16, no. 2, pp. 503-507, 2014.
[35] M. J. King and S. L. Buchmann, "Sonication dispensing of pollen from Solanum laciniatum flowers," Functional Ecology, vol. 10, no. 4, pp. 449-456, 1996.

[36] L. D. Harder and R. M. R. Barclay, "The functional significance of poricidal anthers and buzz pollination: controlled pollen removal from Dodecatheon," Functional Ecology, vol. 8, no. 4, pp. 509-517, 1994.

[37] H. A. Jones and J. T. Rosa, Truck Crop Plants, McGraw-Hill, New York, NY, USA, 1928.

[38] D. H. Duncan, A. B. Nicotra, and S. A. Cunningham, "High self-pollen transfer and low fruit set in buzz-pollinated Dianella revoluta (Phormiaceae)," Australian Journal of Botany, vol. 52, no. 2, pp. 185-193, 2004.

[39] M. A. Aizen, L. Ashworth, and L. Galetto, "Reproductive success in fragmented habitats: do compatibility systems and pollination specialization matter?" Journal of Vegetation Science, vol. 13, no. 6, pp. 885-892, 2002. 

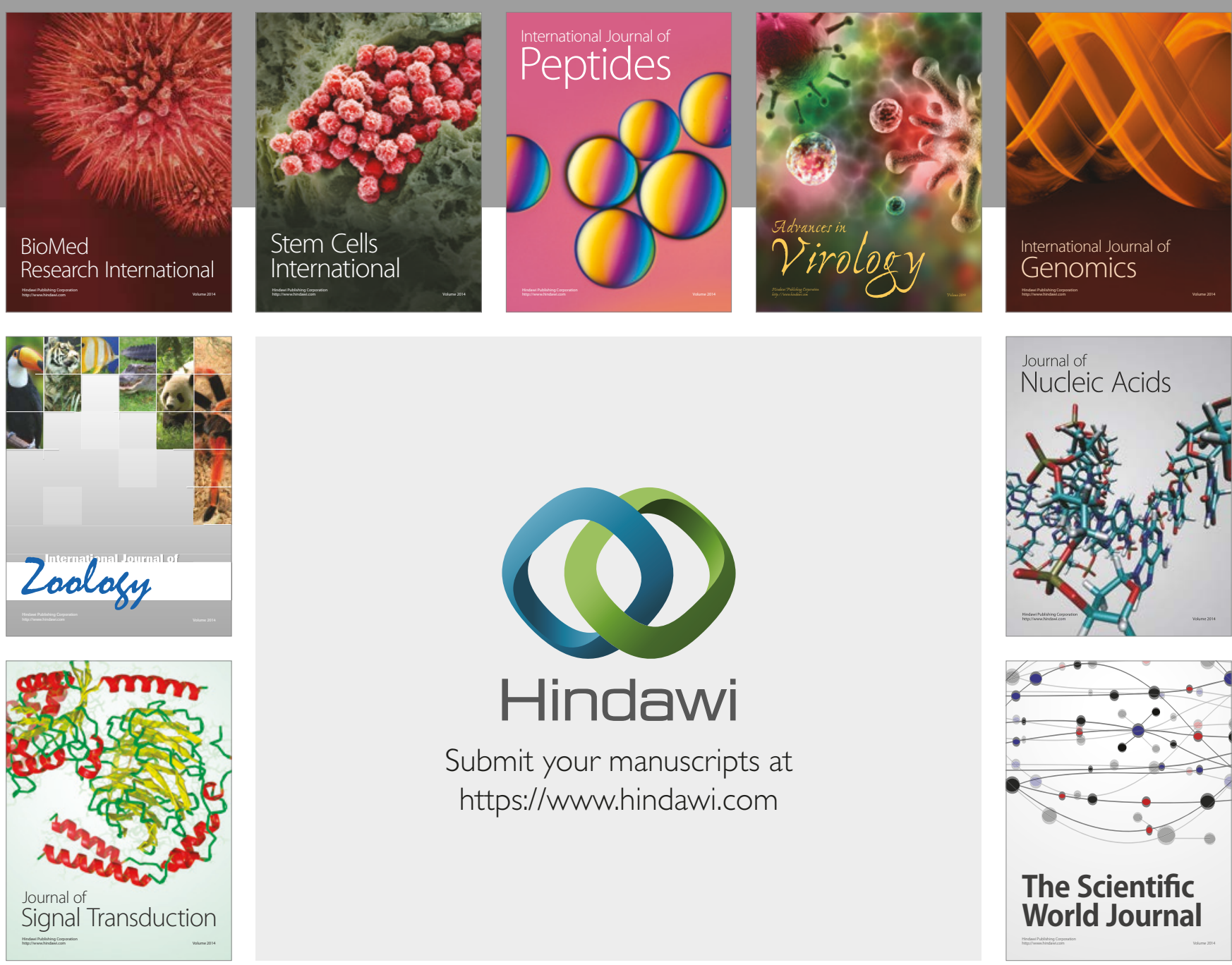

Submit your manuscripts at

https://www.hindawi.com
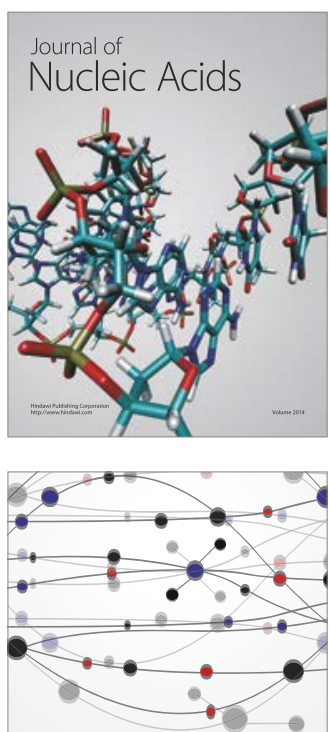

The Scientific World Journal

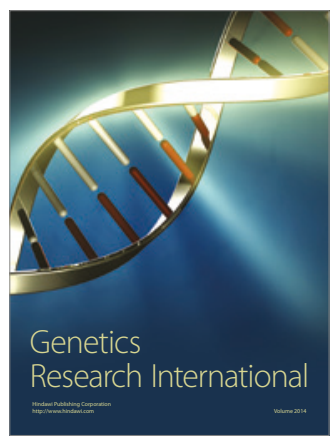

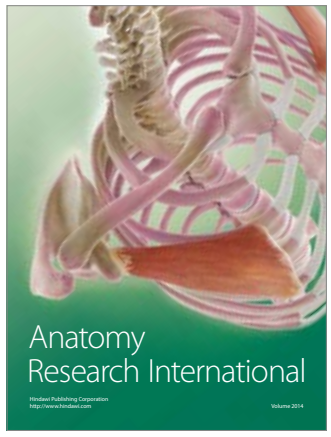

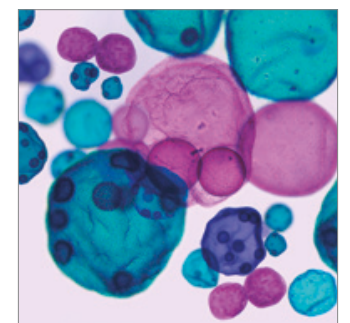

International Journal of Microbiology
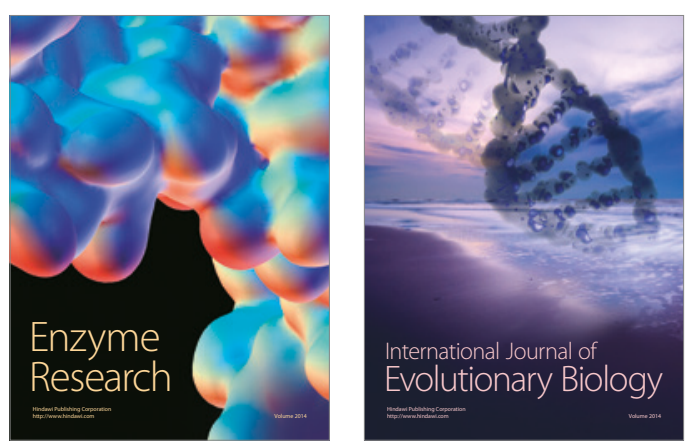
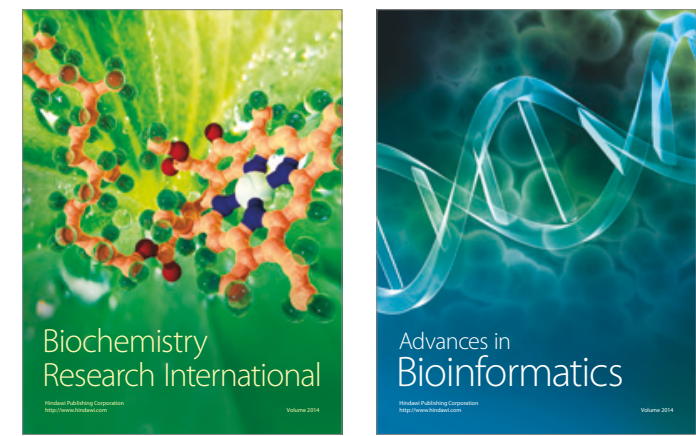

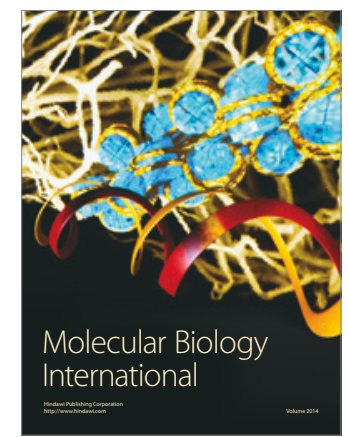

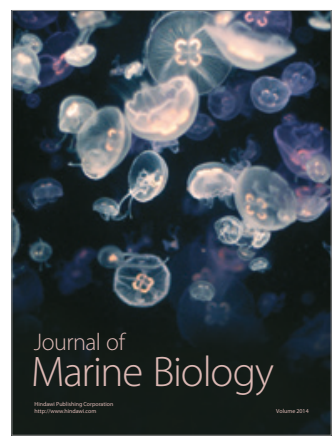

